\title{
Research on Turbocharger Impeller Processing Technology
}

\author{
Zou Jinhong, Zhang Jie, Ye Lan \\ Jiangxi Engineering Laboratory of Digital Manufacturing for Automobile Parts, Nanchang institute of \\ science and technology, Nanchang 330108, P. R. China
}

Keywords: Turbocharger, The impeller, Processing

\begin{abstract}
With the increase of the oil price and the increasingly strict emission regulations, the energy saving and emission reduction technology of the engine has been paid more and more attention. The exhaust gas turbocharging technology can greatly reduce the fuel consumption of the internal combustion engine. In recent years, in order to optimize the performance of turbocharger, the internal flow field of turbocharger has been studied more and more. The performance of compressor was simulated by CFD technology, and the data that were difficult to obtain in the experiment were obtained. The design of compressor was optimized by CFD method. The low speed surge and high fuel consumption of turbocharger are optimized. The performance of compressor was analyzed by CFD method. According to the calculation results, the structure improvement scheme of impeller is proposed and test verification and analysis are carried out.
\end{abstract}

\section{Introduction}

The core components of the turbocharger are the turbine and the compressor impeller (see figure 1), which are connected by a rotating shaft. The working principle of turbocharger is very simple. High pressure exhaust affects the turbine to rotate at high speed. This is a very high speed. Now, the speed of the turbocharged car (12 20) and double, 104r/min, and it drives the impeller to rotate at a high speed and the impeller is compressed air at high speed. The action of a turbine is to turn the kinetic energy of the exhaust gas into a rotating shaft, while the impeller is used to compress the air. fig. 1 is a geometric model of turbocharger turbine impeller. The surface structure of turbocharger turbine impeller is complex, and its structure has periodic symmetry, and the load and constraint have periodic symmetry. In order to ensure the accuracy of turbine blade root calculation and the accuracy of turbine blade root calculation, the turbine impeller is divided into two parts with a radius of $5 \mathrm{~mm}$. The head part adopts UG and imported into finite element method, the rest is part of optimization, and the passenger dedicated line is used in ANSYS. After optimization, the finite element calculation model is divided into 1 cycle, $3 \mathrm{~d}$, and free mesh (figure 1). The axial restraint is applied to the friction welding end of the wheel and the centrifugal force is applied.

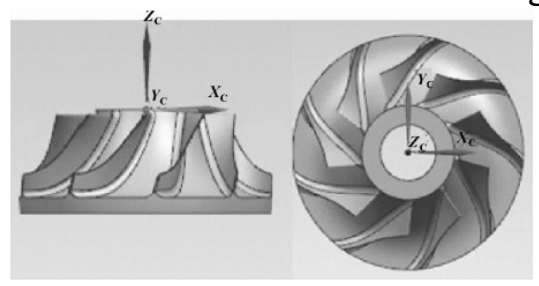

Fig. 1 Turbocharger impeller structure diagram

\section{Turbocharger impeller overview}

The impeller is the heart of the turbocharger. In the turbocharger, the rotor of the turbocharger impeller usually has a very complicated structure (figure 1), when the work of the turbocharger impeller is mainly purifying air, input and transform it into a cylinder kinetic energy as much as possible in order to increase the output power of engine. In this process, the rotation speed of impeller and the edge speed are very fast. Therefore, the flow in the impeller is quite complex and often occurs in such harsh environments as high temperature, high pressure and high corrosion. The 
overall design and production level of the impeller has a great influence on the overall performance of the turbocharger. Therefore, in addition to reasonable design, attention must be paid to machining accuracy and technical requirements.

So the choice of processing and processing equipment is also more important. Keys and the processing difficulties of impellers are all analyzed, and according to the processing, under the condition of existing technology, which is based on five axis and three axis machine tool use, treatment scheme was proposed, and through the impeller UG6.0 and post-process machining tool path of reasonable planning, we can eventually produce a turbocharger impeller which is qualified.

\section{The structure characteristics of the impeller}

\subsection{Matters need attention in impeller processing}

The structure of one impeller observed in fig. 1 is that the basic structure of the impeller is a tapered hub with uniform distribution of blades, and a small and deep space channel is formed between the blades. The shape of the blade is more complex, and the degree of deformation is more serious from the edge of the inlet side of the inlet, which is a typical forward bending type. The blade edge of the degassing blade is $0.45 \mathrm{~mm}$ thick and the inlet edge is $0.4 \mathrm{~mm}$, and the requirements on blade surface quality are also very high. According to this analysis, the following points should be noted in the actual machining process of turbocharger impeller :(1) the blade distribution is relatively concentrated; (2) leaf blade variable section, wall thickness; (3) the rounded corners of the hub and blade are R3.

\subsubsection{Traditional method impeller balance is low}

Because the traditional impeller and turbine are installed on the same rotor, the high speed rotation at work requires relatively high performance. The traditional method of impeller manufacturing is casting and polishing. However, the traditional manufacturing method is inefficient, and it is difficult to guarantee the strength and precision of the blade and channel, which leads to the inefficient turbine supercharger.

\subsubsection{Adopt the five-axis motor}

After optimizing the process plan, the impeller will be machined by five-axis combined motive for the above problems. On the basis of satisfying the requirement of impeller design, reduce the process and production time of the process and reduce the production cost.

\subsection{Analysis of impeller processing technology}

The hub and blade of the impeller are round and complex. Therefore, it should be analyzed according to the reasonable processing technology in different regions. The process analysis and observation of the channel impeller indicate that the two arcs of impeller and hub joint belong to smooth transition connection. Therefore, when we finish machining, we should strictly consider the size of the cutter and the length of the tool.

\subsubsection{Process analysis}

The curved blade is applied to the bottom of the surface, and the following aspects should be paid attention to in the process of the blade :(1) the sleeve of the blade's axis vector, which changes rapidly; (2) internal arc treatment, pay attention to the interference of the cutter shaft and adjacent blades; (3) the maximum thickness of the wall is $0.5 \mathrm{~mm}$, which accords to the machining method of typical parts.

Impeller machining with the application of the following measures: (1) according to fact that the material hardness value is hv410, $6 \mathrm{~mm}$ of carbide end milling ball head the first disc diameter and processing in the blade leading edge of the cuff, the change of cutter axis vector is very obvious, so the dynamic speed optimization of feed rate, and reduce speed. (2) the maximum swing Angle of the knife shaft is increased in the area with the sharp change of curvature, and the unprocessed blade on both sides is set on the surface of interference inspection. (3) the rough finishing of the 
blade adopts the multi-layer cutting mode, and the single feed quantity decreases successively. (4) after the blade is finished, the residual volume of the blade is $0.05 \mathrm{~mm}$, which is ready for the next procedure.

\subsubsection{Impeller processing technology, processing benchmark and material}

Impeller machining technology, standard and materials, which contain coarse, rough machining and rough machining of blade runner, semi-finishing and semi-finishing blade, hub and semi-finishing flow, transition curved surface finishing and finishing wheel and blade surface transition and subsequent processing. The focus of this process is coarse, thin channel analysis. After the three-axis milling of the impeller model, the machining allowance is still very large, but in the process of semi-finishing, a lot of materials are eliminated. (1) although the blade is rough, it must not be larger than the diameter of the mesh spacing knife flow. (2) choose tools not to interfere between the hub and blade Angle. Based on the above considerations, a hard alloy ball milling cutter with a diameter of $10 \mathrm{~mm}$ is processed, and the cutting depth of each layer is 1 AP. Drive mode is a kind of surface drive, the maximum residual height is $0.2 \mathrm{~mm}$; for finishing blades and hubs, it will reach to $0.2 \mathrm{~mm}$;

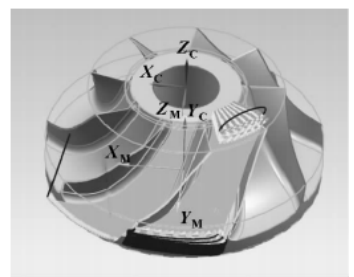

Fig. 2 Rough machining tool path diagram

In order to avoid the knife shaft interference artifacts, the maximum pendulum angle of the knife shaft is 15; interfered by the adjacent blades; The spindle speed is 5000 RPM; the precision runner, and the ball knife diameter is processed to $6 \mathrm{~mm}$. Other parameters also need to make some adjustments. The generated knife track is shown in figure 2. The blade is rough and delicate. Because the blade of impeller belongs to thin-walled parts, it is very easy to deform. In order to avoid this kind of phenomenon, you can take the following measures: (1) in the rough machining of the first players, at the completion of the port of filling materials, support for the blade, can prevent walking in the rough; (2) use multi-layer milling to reduce the single material, and the handle material is harder, so that the knife in the process is consistent with the shape design. The two parts are the maximum curvature of the blade, and the linear interpolation is used in machining the machine, which inevitably produces the nonlinear error. In order to meet the performance requirements of turbocharger, the curvature difference method is used to solve this problem. (3) the blade root is the taper wheel hub, and the blade is connected at the round corner of the roots of R3, and the ball end milling cutter with a diameter of $6 \mathrm{~mm}$ is ensured to be in place. Other parameters are as follows: the cutting depth is $0.1 \mathrm{~mm}$ per layer; One-way cutting mode; The quantity is $0.05 \mathrm{~mm}$ and the maximum length is $0.1 \mathrm{~mm}$. The spindle speed is $6000 \mathrm{r} / \mathrm{min}$. The generated knife track diagram is shown in fig. 3.

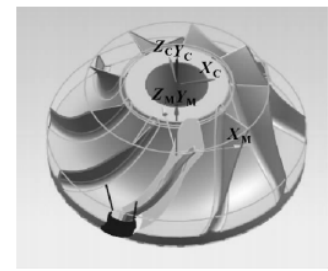

Fig. 3 Impeller finishing tool rail

\subsubsection{Check the post processor}

Numerical simulation and processing because of the turbocharger impeller blade surface deformation, the flow field of the deep, small pitch, machining cutter axis vector change rapidly and 
easily in the practical machining to produce the problem such as lack of interference, colliding, processing. In order to save processing time, it is necessary to verify the postprocessor. Therefore, numerical control machining simulation software (VERICUT7.0) is simulated. The final product has no interference, no machining and other phenomena, and the machining tool path is smooth, and the surface quality and the turbine supercharger impeller are used in accordance with the standard.

\subsection{Blade wheel machining tool path development}

Five-axis cutting has special technical requirements than traditional cutting. In addition to the five-axis cutter and cutter, appropriate CAM programming software is also needed. Five-axis linkage machining system for CAM programming, should have fast interpolation arithmetic, high strength, fully automatic cutting test processing capacity, automatic controller and clamp interference, feed rate optimization, tool path editing and residual analysis functions optimization, and other functions. First, we should pay attention to the safety and effectiveness of the processing method. Secondly, the smoothness of the tool path should be guaranteed as much as possible, which will directly affect the processing quality and the life of the main shaft parts. Finally, in order to make the tool load evenly, it will directly affect the tool life. In addition, the whole impeller blade is thin, the deformation is large, the probability of interference is very high. This is the main factor that affects the quality of the five-axis programming. Even if the above problems are well solved, another important issue is to control the movement in the process of the sudden changes in the tool holder, because sudden change will directly affect the axes of the displacement of the sudden increase, which even affect the movement limit of the machine. The impeller is a typical free surface part, and if the CAM processing strategy is adopted, it needs to be reprocessed in different directions.

Tool selection.

As people's demand for power is more and more strict, the use of turbocharger engine will be wider and wider. In current interference collisions, especially when the blade is used, the cutter is required. It is easy to collide with adjacent blades through the blade passage. It's at the root of the blade. Closed impeller can only be used. The interference and collision of the two clips are not as serious as the interference and collision of open integral impeller. Therefore, in the calculation of tool path, the smoothing processing of tool bar vector generation is the key and difficult point of the tool path without interference. In other words, the tool radius is greater than the maximum circle radius of the connecting part of the wheel and blade. The radius of the selected tool is less than the minimum radius of the flow path and the blade connection part, and in the clearance of the connecting part of the runner and the adjacent blade. The selection of the tool is a round nose knife with a diameter of $25 \mathrm{~mm}$, and a $12 \mathrm{~mm}$ diameter of the diameter of $8 \mathrm{~mm}$ spherical cone diameter (see Fig. 4- Fig. 6).

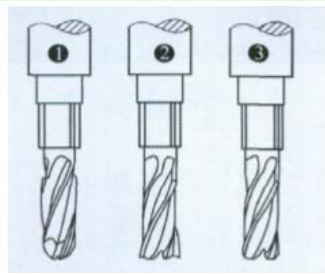

Fig. 4 Rounded nose knife

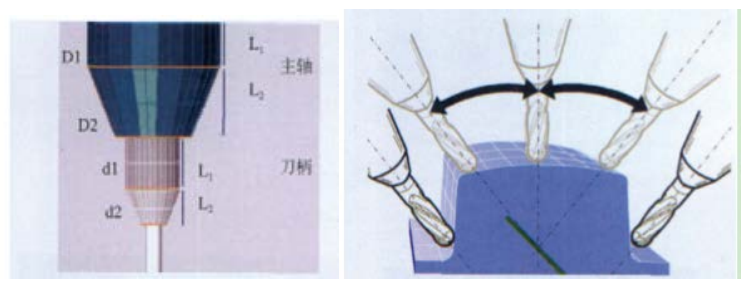

Fig.5 Knife Fig. 6 Taper ball cutter

\section{Design and analysis of turbocharger turbine impeller}

\subsection{Design of turbocharger turbine impeller}

With the purpose of making the weight of turbo impeller is optimized to the minimum weight. The turbine impeller is optimized. On this basis, the turbine impeller casting and assembly process are considered, and the new type of turbine impeller structure is determined, which reduces the weight of turbine impeller by $6.9 \%$. The optimized turbine impeller structure not only saves the consumption of materials, at the same time, the distribution is more reasonable, the quality of the 
rotor of the turbocharger is helpful to improve the mechanical efficiency and reliability of the shaft system of the turbocharger. Strength check and life analysis show that the optimized results meet the requirements.

\subsection{Analysis of core components of turbocharger}

The turbine is the core component of the turbocharger, which consists of a turbine impeller and a compressor impeller. The strength of the turbine impeller is much higher than that of the compressor impeller. The high - cost K418 nickel base alloy is a commonly used turbocharged impeller material. The density of this material is much higher than that of the compressor impeller. Therefore, the quality distribution of turbo turbocharger is very uneven, and the quality distribution of turbo charger rotor is not reasonable. Therefore, the structure of turbine impeller should be optimized.

\subsubsection{Reduce wheel weight}

It is necessary to reduce the weight of the rotor properly. In the common structural optimization design, the optimization criterion method and the software integration of the large finite element analysis program are necessary. Without replacement blades and flow, it can ensure that the basic performance and the turbocharger turbine impeller structure strength, reduce weight effectively, reduce the material consumption, cost savings, and improve the economic benefit. At the same time, it can reduce the inertia of the turbocharger rotor as much as possible, improve the mass distribution of turbine impeller and compressor impeller, and improve the mechanical efficiency of the turbocharger shaft system.

\subsubsection{Consider the effect of temperature difference}

Compared with the full-turbine impeller, the hub diameter is small and the temperature difference is small. And turbine impeller diameter of $55 \mathrm{~mm}$, compressor impeller diameter is 62.50 $\mathrm{mm}$, this is the turbine impeller material K418 alloy under its mechanics performance optimization of load is the minimum burst engineering required speed. This type of turbocharger, the calibration speed of $120000 \sim 140000 \mathrm{r} / \mathrm{min}$, can reach the maximum of $150000 \mathrm{r} / \mathrm{min}$ in China, and the safety coefficient range of the turbine impeller is $1.4 \sim 2$. Therefore, in this paper, the optimal speed is 1.4 times $(150000 \mathrm{r} / \mathrm{min})$ of $210000 \mathrm{r} / \mathrm{min}$ maximum speed, whose calculation formula is the load of the turbine impeller.

\section{Conclusions}

In short, the impeller in the turbocharger is actually processed by modifying the process plan. The impeller is measured with a special measuring instrument. Accord with actual design and actual requirement, the machining method is used to meet the machining accuracy of the impeller, saving the production time and saving the processing cost. In addition, it also provides some experience for the processing of such special parts. It is difficult to process the impeller with five shafts, and the process is complicated. Through the study of the whole impeller machining method, the tool path is optimized, and the correct machining scheme is provided for the five-axis machine tool, which improves the overall machining level of the impeller.

\section{Acknowledgments}

This work was supported by the Nanchang Institute of Science and Technology research project for Jiangxi Engineering Laboratory of Digital Manufacturing for Automobile Parts under Grant No. SZZX-17-23.

\section{References}

[1] Su Yingxu, Li Junqiu. Fit Clearance of Impeller to Turbocharger Performance Influence with 
Mechanics Properties[J]. Applied Mechanics and Materials, 2012,1780(164).

[2] Li Gequ. Study on Processing Technology of Turbocharger Impeller and Shaft[J]. Applied Mechanics and Materials, 2014,3207(556).

[3] Chunjun Ji, Xiaoqing Li. Aerodynamic Optimization Design of a Turbocharger Compressor Impeller[J]. Advanced Materials Research, 2012,1528(455).

[4] MATSUDA, MASAAKI, TANEDA, YOSHIO, HIROTA, SHUICHI, HARIMA, HIDETOSHI, INOUE, NOBUHIKO, YONEZAWA, KOICHI, TSUKIYAMA, TAKASHI. Turbocharger impeller, method of manufacturing the same, turbocharger, and turbocharger unit[P]. AU2014208575, 2016-03-17. 